\title{
Understanding Sleep and Dreaming
}




\title{
Understanding Sleep and Dreaming
}

\author{
William H. Moorcroft \\ Luther College of Sleep and Dreaming Laboratory and Psychology Department \\ Decorah, Iowa \\ and \\ Colorado State University \\ Fort Collins, Colorado \\ with assistance from \\ Paula Belcher \\ Department of Psychology \\ Northwest Christian College \\ Eugene, Oregon
}


eBook ISBN: $\quad 0-306-47949-4$

Print ISBN: $\quad 0-306-47425-5$

C2005 Springer Science + Business Media, Inc.

Print C2003 Kluwer Academic/Plenum Publishers

New York

All rights reserved

No part of this eBook may be reproduced or transmitted in any form or by any means, electronic, mechanical, recording, or otherwise, without written consent from the Publisher

Created in the United States of America

Visit Springer's eBookstore at:

http://ebooks.springerlink.com and the Springer Global Website Online at:

http://www.springeronline.com 
For my loving wife and friend, Christina, who for over 30 years now has supported and encouraged me in my endeavors. She has also been a wonderful traveling companion in so many ways. 


\section{Acknowledgments}

There are so many people and institutions to which I owe a big debt of gratitude. Over the years, so many have helped me know and understand sleep and dreams in so many ways. For opening their labs for visits: Alex Borbély and associates Irene Tobler and Peter Acherman in Switzerland; Jim Horne in England; Eva Svanborg in Sweden; Helmuth Rauscher in Austria; Tom Roth and associates in my hometown, Detroit; Ida Karmanova in Russia; Harvey Moldolsky in Toronto; Mark Mahowold and associates, especially Andrea Patterson in Minneapolis; Peter Hauri at the Mayo Clinic; and Mark Solms in London. For so readily corresponding with me by mail or e-mail: Mary Carskadon, Kathy Lee, Mike Bonnett, Monika Woolsey, Bob Stickgold, Eve Van Cauter, Bob Sack, Ernie Hartmann, Lee Kavanau, and Bob Ogilvie. For visiting and speaking at Luther College: Bill Dement, Gayle Delaney, and Peter Hauri. For sharing rooms while at sleep meetings: I. N. Pigarev, Barry Karkow, and Larry Scrima. For extended conversations at meetings: Bill Domhoff, Kelley Bulkeley, John Shepard, Alan Siegel, Jerry Rosen, Carlyle Smith, Henry Lahmeyer, Carol Landis, Bob McCarley, Merrill Mitler, Misha Radulovacki, Tim Roehrs, and Barry Sterman. For hosting me on sabbatical: Roz Cartwright at Rush Medical College in Chicago and Phil Westbrook at the Mayo Clinic in Minnesota. And finally, for the many students over the years who have worked with me on research and asked insightful questions in class.

I also would like to heartily thank Luther College for granting me a sabbatical leave and the Psychology Department at Colorado State University for providing me with an office and wonderful colleagues while I wrote this book. Additionally, I found the technical assistance from CSU psychology staff members Donna Merwarth and Ginger Lacy most helpful. 


\section{viii Acknowledgments}

My thanks also go out to editors Mariclaire Cloutier and Sharon Panulla at Kluwer Academic/Plenum Publishers, for their assistance and guidance. Also to Paula Belcher for carefully editing my writing and giving advice on its content.

If there are others that I have forgotten to acknowledge, my apologies and my thanks.

Wm. H. Moorcroft, Ph.D. (you can call me Bill)

Fort Collins, Colorado

July 4, 2002

PS. I like to hear from instructors and students who have used this book in a course. For that matter, I also like to hear from any others who may have read it, or parts of it. I will endeavor to keep updating the book as new information comes to my awareness and will try to pass it along to those who may be interested. Try contacting me at moorbill@colostate.edu. Meanwhile, I wish you the best of sleep and the most pleasant of dreams. 


\section{Preface}

As I am writing this, I am anticipating the 50th anniversary of the discovery of REMS. For it was in 1953 that Aserinsky and Kleitman, who, while electronically recording a person's sleep in a University ofChicago lab, were surprised to notice that eye movements occurred periodically even when their subject was, by all indicators, completely asleep. Four years later, Bill Dement—-then a student of Kleitman-discovered the connection between these eye movements during sleep and dreaming (Dement \& Kleitman, 1957). These startling observations began a whole new era of interest in the laboratory study of sleep, dreaming, and subsequently, sleep disorders. From these pioneering investigations came an explosion of discoveries and surprises, frequently leading to revision, including some outright rejection, of established notions about sleep, sleeping, dreams, and dreaming.

This explosion of new information continues today. The number of articles in scientific journals about sleep, dreaming, and sleep disorders in the last few decades easily outnumbers all those that preceded them. New journals devoted to sleep and dreams have recently been born and a number of very fine technical books have been published. However, nothing written within the last decade is suitable for use by undergraduate students as a textbook or course supplement that adequately covers sleep, dreaming, and sleep disorders. This book is intended to fill that void.

I have written this book from several perspectives. First, from the vantage point of a researcher in each of the three areas of sleep, dreaming, and sleep disorders. I have included the results of some of my research in order to show how knowledge about these many facets of sleep has been discovered.

Second, I have written this book out of my experiences with sleep disorders in sleep disorders centers. I have included many actual experiences with sleep disorder patients so that students can better understand the problems that sleep disorders present to their sufferers. 
Finally, I have written this book from my experience as a college professor who has frequently taught courses on sleep, dreaming, and sleep disorders over more than 25 years. This book is written for college students with no prior knowledge of sleep and related phenomena. At the same time, it is not boring for those students that already have some knowledge in these areas. Most people have a natural fascination with sleep and dreams. From this starting place I build to an even greater fascination with, as well as increased understanding of, all aspects of sleep and dreams. I have avoided using technical jargon as much as possible, but some terms, which are included, are critical to know. At the same time I have tried to avoid overgeneralization and oversimplification. In addition, I have endeavored to involve readers as much as possible by talking about all aspects of their sleep and dreaming, as well as taking them to a sleep laboratory during an all-night recording session and having them present while sleep disorder cases are being reviewed in a sleep disorders clinic.

The organization of the book is designed as a journey. Together we will travel first to a modern sleep laboratory to see the cardinal way that sleep and dreaming is studied. It is also intended to both inform readers and heighten their interest in the topic of sleep. From there I will guide you on a climb through the mountains of information that have accumulated about sleep and dreaming. I will take you on an efficient route through these mountains, pointing out the important and scenic highlights along the way. First, we go to the twin peaks of what is known about sleep and what causes us to sleep. Next, we visit the dreams-and-dreaming mountain, after which we travel over to the mountain of sleep disorders. We conclude our journey by climbing to a high vantage point overlooking these mountains of information from which we can explore what might be the functions of sleep and dreaming.

More specifically, the first section of this book starts with a chapter on the basics of sleep (Chapter 1) which describes the specific criteria for sleep and its sub-stages as measured in the lab, what a typical night of sleep is like, and how it changes with age. It includes information on sleep in animals. This is followed by a chapter (Chapter 2) that presents sleep as a recuperative need and as a rhythmic process. Chapter 3 looks at variations of these basics including the effects of sleep loss.

The second section focuses on the brain in sleep and the body in sleep. Chapter 4 presents a brief overview of the structure, basic chemistry, and functioning of the brain, with an emphasis on those aspects most important for sleeping and dreaming. Chapter 5 discusses how sleep affects the body and how the body affects sleep.

The third section turns to dreams and dreaming. Chapter 6 looks at what is known about the nature and content of dreams. Chapter 7 then turns our attention to the process of dreaming. In Chapter 8 , the key aspects of the major theories about dreaming, as well as methods of dream interpretation, are summarized.

Section four brings us to sleep disorders. In Chapters 10 and 11 the major types of disorders treated at sleep disorder centers are presented, usually introduced by illustrative case examples that bring the problems to life for the reader. Before that, in Chapter 9, is a look at other difficulties people may have with sleeping and dreaming. 
Finally, section five is a summary of what sleep and dreams are all about. On the basis of what has been learned about sleep, dreaming, and sleep disorders, the probable functions of sleep and dreaming are reviewed and discussed. Chapter 12 includes functions of all of sleep and non-REM sleep. Chapter 13 continues with functions of REM sleep and dreaming.

In the end, I hope that readers will gain increasing fascination and knowledge about sleep and dreaming from reading this book. I know I have, while writing it. 


\section{About the Author}

I am often asked about how I got interested in sleep and dreams. I reply with a little story.

"Everyone in the lab is going to the international sleep meeting in Europe. Why don't you come along? The round trip charter flight is only $\$ 180.00$. The meeting lasts for 5 days but the flight does not return for another 25 days after that."

I heard this when I was doing postdoctoral research on the maturation of brain waves in baby rats at the University of Nebraska Medical School shortly after receiving a Ph.D. in psychology, actually psychobiology, from Princeton University. I went. I admit that the main reason was to spend a month in Europe. However, what I learned at the meeting, held in the summer of 1971, fascinated me. It was the beginning of a continuing interest in sleep and all of its ramifications.

Shortly after my return from Europe, I began to teach at Luther College and found myself reading and lecturing frequently about sleep. Within a few years, my research interests shifted away from baby rat brains to sleep. Soon I started a sleep research laboratory at Luther College in which I have studied various aspects of sleep and dreaming. I also kept on attending the meetings (some in Europe, others in places like Cap Cod and San Antonio) of what was to become the Sleep Research Society. Later I attended the inagural meeting of the Association for the Study of Dreams (in San Francisco). In 1980, I learned about sleep disorders and did some research in that area while on sabbatical at the Sleep Disorders Center, headed by Rozalind Cartwright, of Rush Medical School in Chicago. My interest in dreaming was piqued during this time, since Dr. Cartwright had already done landmark research in this area. Later, I was on another sabbatical at the Mayo Medical Center's Sleep Disorders Center in Rochester Minnesota. While at Mayo, I again did some sleep disorders research.

I love sleep and dreams, pun intended. I have continued to study, research, lecture, and write about sleep, dreaming, and sleep disorders. And of course, I have to continued to attend those wonderful meetings. My intention is to keep on keeping on with these things until I am no longer able to do so. 


\section{Contents}

Prologue: A Visit to a Sleep and Dreams Lab

Part I: SLEEP AND SLEEPING

1. What is Sleep and How is it Scientifically Measured?

2. The Need to Sleep

3. Normal Variations of Sleep

Part II: WHAT CAUSES US TO SLEEP?

4. The Brain in Sleep

5. The Body during Sleep

Part III: DREAMS AND DREAMING

6. Dreams

7. Dreaming

8. Theories of Dreams and Dreaming

Part IV: PROBLEMS WITH SLEEPING AND DREAMING 201

9. Some Difficulties That People May Have With Sleep 205

10. Disorders of Sleep, Part I 231 


\section{xvi Contents}

11. Disorders of Sleep, Part II 245

Part V: WHY WE SLEEP AND DREAM 261

12. Functions of Sleep and NREMS 267

13. Functions of REMS and Dreaming 285

$\begin{array}{ll}\text { Epilogue } & 311\end{array}$

$\begin{array}{ll}\text { Notes } & 317\end{array}$

$\begin{array}{ll}\text { References } & 321\end{array}$

$\begin{array}{ll}\text { Index } & 333\end{array}$ 


\section{Prologue A Visit to a Sleep and Dreams Lab}

If you were asked to determine if someone is asleep, what would you look for? You probably would check the person's eyes to see if they were closed, see if the person were relaxed and still, be sure they are not very responsive to stimuli, were breathing regularly, and so on. But you, like just about everyone, have at one time or another done all of these things to fool other people into believing you were asleep. Then, too, someone in a coma shows all of these signs, appearing to be asleep. It is apparent that you cannot tell very accurately if a person is asleep simply by observation. Alternatively, you could wake the person up and ask if they were asleep, but you then depend on that person's ability to willingly and accurately tell you and, of course, the person is then no longer asleep. It is rather like the joke my father used to tell: "Says one Englishman to another, 'Were you in the boat when the boat tipped over?' 'No, you blithering idiot, I was in the water!" "

There are two important implications of this inability to observe whether or not another person is asleep. First, until the middle of the twentieth century, there was little scientific study of sleep. Thus, much of what is known about sleep is new knowledge, and some of it is surprising, since it is contrary to popular beliefs. Second, most study of sleep has taken place in a sleep lab where the sleeper is attached to sensitive instruments allowing objective determination of sleep without disturbing it. (Although the development of miniaturized portable equipment has allowed increasingly more sleep research to be conducted outside the lab.) Sleep labs have only been in existence since 1953 when Aserinsky and Kleitman first reported that sleeping people have two different kinds of sleep. Today, there are many sleep labs all over the world

Adapted from Moorcroft, 1993, with permission of the publisher. 
engaged in exploring the mysteries of sleep every night. Let me first take you on a visit to a sleep lab before we discuss what is known about basic sleep processes.

\section{A VISIT TO A SLEEP LAB}

We arrive at the sleep lab a little before 10 p.m. and walk down a pleasant, carpeted hallway that has several doors on either side. We are directed to an open door leading to a brightly lit room.

The "subject" for tonight's study is a paid volunteer who has changed into her pajamas and is sitting next to a small table partially covered by a clean white towel. On this table are some rolls of medical tape, a few bottles, scissors, a toothpaste-like tube, some gauze, a comb and hair clips, a tape measure, an electrical meter, and other similar things. On the nearby wall hang a dozen or so long wires with disc-like enlargements on one end and metal pins about the size of match sticks on the other end. The 23-year-old subject has short, black hair done in one of the latest styles. She has bright, attentive eyes.

Also in the room is a man in his mid 30 s in a white lab coat. He is on the tall side and slender, with a neatly trimmed dark mustache. He pleasantly turns to us and says, "Hi. I'm Sam, the sleep lab technician. This is Joan. She will be our sleeper tonight. Joan has been here before, so she knows what we are about to do. As I get her ready, I will describe what I am doing and why I am doing it."

"First we have to apply several wires to Joan's head. They are called electrodes, but think of them more as antennae." As he is talking, he has us inspect one of the wires. Up close, the disc end looks about the size and shape of half a pea and is hollow." This disc is a gold plated electrode. Other types of wires have plastic ends or thick adhesive tape with just a little silver foil embedded inside. They all work the same, but the metal ones are easier to put on the hairy scalp, while the others work well on bare skin."

Meanwhile, he has started to make precise measurements of Joan's scalp with the miniature tape measure and marks it with a special, soft, red pencil. "The electrodes have to be placed on specific locations on the head several inches above each ear called $\mathrm{C} 3$ on the left side and $\mathrm{C} 4$ on the right side and another at the back of the head at $\mathrm{O} 1$ or $\mathrm{O} 2$. The same measurement technique is used worldwide to apply electrodes. That way results from any lab can be directly compared." He carefully marks a spot on each side of the head about one-third of the way down from the center of the top of the head toward each ear. He picks up the comb and several hair clips and parts the hair over the marked area on the right side. Then he picks up a cottontipped stick and a bottle of liquid.

"Our bodies are covered with a layer of dead skin plus oil." Turning aside to us with a wry smile on his face, he says in a confidential tone, "That kind of takes the glamour out of looking at a good-looking movie star-all you see is dead skin." Turning back to Joan, he proceeds to moisten the cotton-tip with a gooey solution from one of the bottles and to rub the exposed marked area. "This process removes 
the dead skin and oils to enable better electrical reception by the electrode." With another wry smile, he turns to Joan and says, "The green color in your hair will grow out in about nine months."

Laughing, Joan replies, "You can't fool me. I've been through this before."

Turning to us, Sam explains, "Actually, all of this stuff is very harmless and easily washes out." He then picks up the toothpaste-like tube. "This substance is electrode gel. It also helps make better electrical contact." As he is talking, he takes the electrode from us and squeezes enough gel into its hollowness just to fill it. Then he carefully places it on the prepared spot on Joan's scalp and has her hold it in place with her left forefinger. Working quickly, he takes the top off a glass petri dish and picks up a moistened piece of square gauze about the size of two big postage stamps. "It's soaked with a biological glue." Sam places the gauze on top of the electrode, being careful not to disturb it. Again, holding all of this in place with his left hand, he uses his right hand to pick up a metal pencil-sized object attached to a small rubber lab hose. While using the dull tip of the object to hold the electrode and gauze in place, he presses a foot switch and a stream of air hisses through the hose and out of the object toward the glue-soaked gauze. Deftly, he pats his fingers on the gauze around the electrode as the glue dries. Fifteen seconds later, he turns off the air stream and sets the apparatusdown. "The electrode will stay in place all night now. If I were to give a gentle but firm tug on the attached wire, Joan's head would tilt toward me."

"He thinks I'm a puppet on a string," she playfully complains.

"Not to worry. I will easily remove it in the morning by dissolving the glue."

"What does the electrode do?" you ask.

While repeating the application procedure on the other two marked spots on Joan's head, he tells us, "It allows us to record her brain waves (on what is technically called the EEG or electroencephalogram). As you will see, there are brain waves specific to sleep."

Having finished applying the three scalp electrodes, Sam cleans the skin near the outer corner of the left eye with another cotton-tipped applicator moistened with the gooey solution. He then presses one of the adhesive electrodes onto the prepared spot. Next, he places a piece of hypoallergenic surgical tape over the electrode and surrounding skin. Giving a little jerk on the wire, he says, "That one will also stay in place all night."

As he similarly applies another adhesive electrode at the outer corner of the other eye, he explains, "These electrodes will enable us to measure her eye movements. The eyes are like little batteries with the positive end in front. When the eyes move, the positive front moves closer or farther from the nearby electrode, thus changing the electrical influence on the electrode. In this way, we get what you might call 'eye movement waves' (actually the EOG or electrooculogram). Like brain waves, eye movements help us to determine when Joan is asleep and what kind of sleep she is in."

He then attaches two additional electrodes on Joan's chin as he explains, "These electrodes let us record neck muscle tension. Electrical changes occur when muscles contract. The more contracted or tense a muscle, the more electrical activity. This procedure enables us to assess how relaxed the muscles of the neck are. You see, as 
long as we are awake, our neck muscles maintain tension in order to hold our head up, even when we are resting our heads on a pillow. This neck muscle tension or EMG (for electromyogram) gives us another indicator of the presence of sleep and the stage of sleep." Turning to me, he asks, "How can you tell when students fall asleep during your lectures, Dr. Moorcroft?"

I reply, "Well, of course they never do." After a few seconds of silence accompanied by stares of disbelief, I continue. "O.K., so once in a while a student may doze off. How do I know? Well, let me see. Ah, they don't answer my questions or take notes and their heads are dropped."

"That's it! Their heads drop because during sleep the neck muscles relax. Also, as we shall see, in one kind of sleep the muscles are almost totally relaxed."

"You mean there is more than one kind of sleep?"

"Yes, We all cycle in and out of different kinds of sleep each night!"

"Is she ready now?" you ask.

"Not quite." Sam replies, as he reaches for three more electrodes. "These pieces of equipment are called ground and reference electrodes." As he prepares and attaches one to the middle of the forehead, he continues, "This one prevents other electrical 'noise' from interfering with our recordings. Have you ever had a portable radio get louder and clearer as you reach out to adjust the knobs?"

"Yes," you reply.

"That happens because you are acting as an antenna for the radio. You see, your body is constantly receiving all sorts of electrical signals - from radio, TV, and all sorts of electrical appliances and motors. Many of these signals are stronger than brain waves and the rest of what we measure. By applying this electrode, we can get rid of this electrical garbage."

He then proceeds to put the final two electrodes on the bony knob behind the bottom of each ear.

"What do those electrodes do?" you ask.

"They are called reference electrodes. Anything we record needs input from two electrodes. Activity on one is actually compared to activity on the other. Sometimes both electrodes are from active areas such as two parts of the brain, and the resulting record is the difference in activity between the two. A lot of other times, it is better if the comparison electrode has no electrical input of its own so that the record shows all of the activity from the active electrode. There is not much electrical activity behind the lower ears, so they work well as comparisons. One of these reference electrodes that I'm applying now is used as a comparison to both eye electrodes and scalp electrodes and sometimes to one chin electrode."

"Wait a minute. What about the other scalp electrode and reference electrode?"

“They're back-ups. We usually don't use all of the scalp electrodes at one time either. The one at the back of the head is useful for determining sleep onset but not of much use otherwise, so sometimes we only use it in the beginning of the night or don't even bother to use it at all. We also only use one of the two electrodes over the 
ears. If something prevents us from recording from one of these, we can easily switch to the other one without disturbing Joan. Otherwise, we might have to wake her up to attach another electrode."

"Can I go to sleep now?" asks Joan, barely stifling a yawn.

"Soon. Just a few more things to do." He tapes some of the loose wires to her face, directing them all to the back of her head, shaping them into a ponytail with some more tape.

"All set."

"Great. (Yawn) I'm tired."

After Joan uses the bathroom, Sam leads her to another room, with us following. The room resembles a small but cozy motel room with a bed, a nightstand and lamp, a chair, florescent overhead lighting, and carpeting. The bed has a green blanket neatly tucked in at the sides of the mattress and two pillows above the folded end of the top sheet. On the nightstand facing the bed is a speaker with an attached microphone. In the corner of the room opposite the bed is a very small infrared TV camera and infrared light mounted near the ceiling.

After Joan lies down in bed, Sam plugs the color-coded wires into a cable coming through the wall. The wires are long enough to allow Joan to move around easily in bed.

"Are you comfortable?" he asks.

"Very much," she replies.

Sam leads us out of the room and closes the door.

"How can she sleep with all those wires on her?"

"Most people have little trouble, especially after the first night. Think how hard it is to stay awake all night, especially in a quiet room and in a comfortable bed."

We walk across the hall to another room labeled Control Room. As Sam opens the door, we see a room about the size of the bedroom except lined with several computers, TV monitors, and other electrical equipment. There are trails of various colored horizontal lines on the computer screens, some of which are straight and others showing various constantly changing waveforms. "The wires from each bedroom feed into one of these computers. This one here is showing the recordings, called a polysomnogram, from Joan. I previously made careful adjustments and calibrations for the five channels we will be using. The top line is from her left eye, the second line from her right. The third line is the muscular activity from the chin electrodes. The fourth and fifth lines are for the brain waves-one from above one ear and the other from the back of the head.

Sam flips a switch on an intercom next to the computer. "Joan, can you hear me?"

"Just barely." He adjusts the volume.

"How about now?"

"Fine. Real fine."

"O.K. Remember to stay awake while I make adjustments to the machine." 
"O.K., but don't take too long or I might be gone."

As Sam types on the keyboard, the lines on the computer get larger or smaller. The eye movement lines look like mirror images of hills and mountains. The EEGs are small, rapidly, but irregularly, oscillating lines, such as a very nervous person might make if trying to draw a straight line. The EMG does not look like a line at all, but rather a thick band made up of many vertical lines of random heights, somewhat like a magnified side view of a shag carpet. Suddenly, all the lines become wide, irregular, thick tracings. This pattern stops after a second or two as abruptly as it started, and the lines return to their previous patterns of movements.

"What was that?" you blurt out.

"She moved. She probably was trying to get more comfortable. We'll occasionally see that all through the night. It actually is useful, because it tells us how restless the sleep is."

Sam continues to look at the record while making some adjustments using the keyboard. Finally, satisfied, he turns to us and says, "Now, we will see if everything is working as it should." Pulling on the intercom switch he says into the microphone, "Joan, I'd like you to do a few things for me now."

"O.K."

"First, look up.” Pause. "Look down.” Pause. "Look up.” Pause. "Look down." Pause. "Look right." Pause. "Look left." Pause. "Look right." Pause. "Look left.” Each time he gives a command, he types a notation of it on the screen. The eye movement lines seemingly respond to his commands, moving toward each other, almost touching when Joan moves her eyes up or to the right and away from each other when the eyes move down or to the left.

"Now blink five times." Again the top two lines respond but this time producing what looks like a row of five dunce hats. Again, Sam notes his instruction to Joan on the screen.

"Now grit your teeth." This time, the thickness of the muscle line triples. "That's fine." Now addressing us he says, "The muscles of the neck contract when a person grits their teeth and the polysomnograph shows it. Next, we'll check the EEG and at the same time get a sample of another kind of brain wave."

"Joan, close your eyes and blank your mind, but don't fall asleep."

"(Yawn) I'll try," came the sleepy voice in return. As Sam makes a notation on the screen, the EEG lines begin to change from their low, fast, random pattern (called beta waves) to higher, slightly slower, but very rhythmic and regular patterns, looking somewhat like a folded ribbon candy viewed from the side.

"These patterns are alpha waves. They occur when a person's mind is awake but relaxed and not particularly concentrating on anything." When he flips the intercom switch and tells Joan to open her eyes, the alpha waves change back to the beta waves.

"Alpha waves also occur when a person is drifting into sleep. What you saw before the alpha waves, and are seeing now, are the beta waves of an awake, alert mind."

"Well, Joan, its time. Call me if you want to get up or need anything, O.K.?" 
"O.K."

"Goodnight." he types a notation into the computer as he switches off Joan's sleep room lights with a remote switch near the intercom.

We all watch the screen closely. Not much happens at first other than an occasional body movement. In several minutes, the EMG becomes less thick to about half its original size, more alpha waves appear, and fewer eye movements can be noted. Then the eye channels trace out lines that look like mirror images of rolling hills, and the EEG becomes much more jagged, but the waves are not as rapid as beta nor as rhythmic as alpha. "These waves are the signs of the start of sleep-so called slow rolling eye movements and the replacement of alpha waves with slower, less regular theta waves in the EEG. It's a light sleep called stage 1 . She will probably spend very little sleep time in this stage. It's more of a transition between stages."

Soon Joan's eyes stop moving, and the EEG line gradually oscillates less rapidly than before, but it is still rather jagged. Then it more rapidly and regularly oscillates for about a second, producing a wave that looks like compact alpha. "That's a sleep spindle, a sure sign of stage 2 of sleep." Soon there is a sudden, large, upward movement, then down past midline, then back to its previous activity level, resulting in a pattern resembling an upside-down pointed ice cream cone next to a smaller but right-side up cone. "A K-complex, another characteristic of stage 2."

This pattern continues for another 10 minutes-occasional spindles and K-complexes on a background of irregular but slower and slower activity. Then the EEG begins to show occasional large sonorous movements and fewer and fewer spindles and K-complexes. When about $20 \%$ of the record is of this pattern, Sam explains, "These are slow waves, also called delta waves. They indicate the presence of slow wave sleep, abbreviated SWS. In many ways, this sleep is the deepest sleep." Soon much of the record contains delta waves and continues this way with little change for about half an hour.

Suddenly, all of the lines become large and blurred indicating a body movement. We confirm this recording when we look up at the TV monitoring Joan and see that she is rolling over. When things settle down, the record again resembles stage 2 with moderate, jagged background and spindles and Ks.

Exactly 93 minutes after sleep onset, the EMG becomes almost a thin, straight line. Suddenly, the eye movement channels burst into activity, showing large, jagged, mirror-image mountains for a few seconds, then falling silent. "That recording is a burst of rapid eye movements. Joan is now in another kind of sleep called REMS (for rapid eye movement sleep). Look closely at the EEG. Notice no spindles or Ks are present and many of the brain waves look like the teeth of a saw blade." Just then there is another burst of eye movement lasting longer than the first. "As you can see, sleep is not a single entity, but is made up of several different states."

The REMS period does not last long. After a few minutes, another body movement occurs and stage 2 returns for 10 to 15 minutes followed by more SWS.

And so it goes throughout the night. Joan cycles between the stages, except there is less and less time spent in SWS (in fact, almost none at all in the second half 
of the night) and more and more time in REMS. Most time however is spent in stage 2-about half of the night. Around every hour and a half, she starts a REMS period.

It is interesting to observe what is happening to us as we stay up all night to watch Joan sleep. It is especially hard for us to keep awake when nothing exciting is happening, like long periods of stage 2. We have to stand up and keep moving or keep talking. Otherwise, a brief sleep overtakes us. Several times we catch each other drifting off and, in a fun way, scold one another. It seems to get cold in the room between 3 and 5 a.m. We check the thermostat and find that the temperature remained unchanged. We later realized that this time was also the time when it was hardest to stay awake.

At 6:15 a.m., through blurry eyes, we can see that the pattern on the computer screen is changing. Several body movements occur, and the EMG gets thicker again. The EEG becomes low and fast and random, and the eyes start moving, not as rapidly as during REMS and more continuously. "She's awake now," Sam informs us. "Good morning," he intercoms to Joan and turns on the light.

"Ugh—oh, mornin" ", (Yawn).

"I'll come in and unplug you now."

"Yeah. O.K."

We follow him in. "How do you feel? Sleep well?"

"Hey, I slept like a log. How about you?"

"Oh, be quiet," he blurts out with a smile.

Now unplugged, Joan is led back to the room with the equipment table. We follow. She sits in the chair next to the table as Sam soaks some gauze in solvent, and then puts a moistened cotton puff over each of the glue-stiffened gauze patches on Joan's head. In about 30 seconds, he lifts both pieces of gauze and the underlying electrode from the left side of her head, and then repeats the procedure on the right side and the back. With another solvent-wet gauze square, he carefully wipes at the area where each electrode rested, then combs the hair back into place. Next, he peels off the tape holding the wires close to her face, and then removes each of the rest of the electrodes in turn. Using a tissue, he wipes off the electrode cream that remains on the skin.

We say good-bye to one another before Joan heads for the shower and Sam returns to the control room to do some post-sleep polysomnograph checks. "See you again tomorrow night," he says as he disappears into the control room. We start to float out of the sleep lab in our sleepless, dazed state, toward our own beds in search of our own quota of that sweet commodity that we have been scientifically observing all night.

\section{A SECOND NIGHT IN THE SLEEP LAB}

"I hope you slept well during the day today," I say, "after being up all night."

"Well, I slept but not as well as usual," you reply. "I was kind of restless and woke up a lot, but I'm O.K."

"Sounds typical for daytime sleep. Tonight Sam will awaken Joan at various times during the night to collect dream reports." 
"I can't wait. I hope she has some wild ones."

"You may be surprised," I comment, "at just how dull they are!"

"Hi, Sam. Here we are for another night."

"Oh, hi. I just about have Joan ready, so it won't be long now." At that moment she came walking out of the preparation room carrying the ponytail of wires leading from the electrodes on her head and face.

"Not a bad way to earn 75 bucks—-sleeping," she says to us.

"It's not all sleep tonight," Sam reminds her. "I will be waking you at various times throughout the night and asking you to report whatever is going through your mind at the time. You may be dreaming or thinking or may have nothing at all going on at that time. That's all right. I just want to know what is going on in your mind when I wake you. All reports are equally valuable."

"Oh well, it's still an easy 75. See ya in the morning."

By now she is in bed and the electrodes are connected to the cable coming from the wall. Soon Sam has turned the machine on, made adjustments, and assured himself that everything is working fine and that Joan is asleep.

"Dreams," Sam says, "can be explored much better in the sleep lab, because we can catch their recall when they are fresh. Tonight, we will wake her three timesfirst during SWS, then during stage 2, and finally during REMS. Watch for differences in what she reports in each stage. The questions I ask are a bit formal, but they have to be the same every time to be sure we don't miss something.

Soon we see the signs on the moving chart that she is asleep and moving down through the stages. Then at 12:07, ten minutes into the first SWS period, Sam turns on a tape recorder and begins. "Joan ... Joan ... JOAN!"

"Ugh ..., oh-ah ..."

"Joan?"

"Yea." Yawn.

"What was taking place just at the moment you were called?"

"Nothin'. Nothin' was happenin'."

"At that moment would you say that you were awake, drowsy, in light sleep, or in a deep sleep?"

"Deep. It was good sleep."

"Was there any visual imagery? If yes, describe it."

"Well, yeah, kinda. A woods, some trees, you know."

"Were there any distortions in the way familiar people or objects were represented?"

"No, not really. It was kinda vague."

"Were you an active participant in what you experienced or just passively observing it?"

"I just saw it."

"Were there any other persons in this experience?"

"No, none; just trees."

"During this experience were you aware that you were here in the laboratory?" 


\section{Prologue}

"No."

"During this experience were you aware that you were observing the contents of your own mind, or did you feel that you were observing or participating in events out in the real world?"

"Sort of real world, but fuzzy."

"How vivid an experience was this: very vivid, moderately vivid, or quite vague?"

"Kinda vague."

"How realistic was this experience: very realistic, a mixture of real and unreal, or very unrealistic?"

"A mixture, I'd say."

"How emotional was this experience: very emotional, only mildly emotional, or very unemotional?"

"Not at all emotional. No emotion."

"How pleasant was this experience: very pleasant, neutral, or unpleasant?"

"Neutral."

"Were you dreaming or thinking?"

"I don't know. Kinda thinking, I guess. But not thinking hard or rationally."

"O.K., you can go back to sleep now."

After Sam turns off the tape recorder, you state, "That wasn't really much of a dream, was it?"

"No." he replies, "That's typical,though, of what you get in SWS sleep-something like a fuzzy photograph. Many times you get nothing."

At 3:10 a.m., ten minutes into stage 2, Sam says, "It's time again," as he turns on the tape recorder,

"Joan."

"Ah, yeah," followed by a strain in her voice indicating that she is stretching.

"What was taking place just at the moment you were called?"

"I (yawn) could not find the classroom where I had to take the final exam. It was like I kept trying one door after another but never finding the room."

"Was there anything else?"

"No, that's pretty much it. It was not real clear."

"What about the visual imagery? Can you describe it?"

"Not very well. I just knew I was opening non-descript doors, looking for the classroom."

"At that moment would you say that you were awake, drowsy, in light sleep, or in deep sleep?"

"I was asleep alright, but it did not seem like it was deep sleep."

"Were there any distortions in the way familiar people or objects were represented?"

"It was not real clear. I just kinda knew what everything was."

"During this experience, were you aware that you were here in the laboratory?"

"No. I thought I was really there, yet it did not seem entirely real." 


\section{Prologue}

"During this experience, were you aware that you were observing the contents of your own mind, or did you feel that you were observing or participating in events out in the real world?"

"Neither. It was kinda dreamy. Oh, sorry about the pun."

"That's ok. I understand. How vivid was this experience: very vivid, moderately vivid, or quite vague?"

"It was moderately vivid to a bit vague."

"How realistic was this experience: very realistic, a mixture of real and unreal, or very unrealistic?"

"I did not think about it while I was experiencing it, but reflecting on it now, it seems almost unrealistic. Incomplete."

"How emotional was this experience: very emotional, only mildly emotional, or not emotional?"

"Surprisingly, not very emotional. I was concerned about missing the exam, but I did not feel emotional about it."

"How pleasant was this experience: very pleasant, neutral, or unpleasant?"

"It was O.K. Kinda neutral, I guess."

"Were you dreaming or thinking?"

"More dreaming than thinking."

"You can go back to sleep now."

Sam turns the tape off as he says to us, "That was pretty typical of stage 2. Not much going on but often repeated over and over again. Also, the experience was not real clear. Sometimes, though, we get a real story. That kind of experience is more likely toward the end of the night."

"What happens in REMS?" you ask.

"Just wait."

Five twenty-three a.m., ten minutes into REMS.

"Joan, ..., Joan."

"Ugh ... yea!"

"What was taking place just at the moment you were called?"

"Well, I was in a shed-you know a tin type shed-with many people, some of whom I knew. I was standing on one side of the building around some cars with a couple of middle-aged men and a couple of girls around 20 years of age. Something had happened to one of the cars, an older model, and the girl was upset. At that point my attention was distracted to the other half of the shed where a guy about 20 years of age was showing films of - I guess it was her vacation or something-while others of the same age watched. Right then, the scene shifted to some body of water like a lake or something. I was driving a speedboat, while the male who was showing the film was swimming in a scuba suit. It's crazy, but he was going the same speed as the boat. Then you woke me up."

"At that moment, would you say that you were awake, drowsy, in light sleep, or in deep sleep?" 
"Oh, I was asleep alright; it was sound. I guess I would have to say somewhat deep."

"Were there any distortions in the way familiar people or objects were represented?"

"People? No. But, the cars were all funny pastel colors and kinda wavy, shimmering. That's all I can remember."

"During this experience, were you aware that you were here in the laboratory?"

"Oh no. It seemed real, like I was there."

"During this experience, were you aware that you were observing the contents of your own mind, or did you feel that you were observing or participating in events out in the real world?"

"It seemed real at the time, but now that I think about it, things were kind of flat or quiet. You know, not very emotional or something. Like spacey."

"How vivid an experience was this: very vivid, moderately vivid, or quite vague?"

"It was vivid, quite clear."

"How realistic was this experience: very realistic, a mixture of real and unreal, or very unrealistic?"

"It seemed realistic while it was happening, but now not all of it seems like it was real. A mixture I guess."

"How emotional was this experience: very emotional, only mildly emotional, or not emotional?"

"There was some emotion. Kinda like something was not right."

"How pleasant was this experience: very unpleasant, neutral, or unpleasant?"

"It was O.K. Toward unpleasant, I guess."

"Were you dreaming or thinking?"

"Dreaming. No doubt about it, I was dreaming."

"Goodnight. You can go back to sleep again."

"Night."

Turning to us, Sam says, "That experience was a fairly typical dream-like a TV program with action and a sequence of events, but scenes can jump forward, backward, or parallel. I did not have to ask all of the standard questions either, since she had already indicated what the answers would be."

We decide to leave early, since there are to be no more dream reports collected and we are tired from the night before.

"Thanks Sam and say good-bye to Joan for me," you say on your way out of the door.

"I will" he replies. "Good-bye."

Turning to me as we walk down the hall, you ask, "Where was all the sex and violence in the dreams?"

"That's just it. There usually isn't any. Most dreams are pretty dull when you get right down to it." 
"Do we always dream during REMS?" you ask.

"People will give a dream report like this one over $80 \%$ of the time when awakened during REMS, even if they state before-hand that they never dream."

"Well, thanks again," you call out as you turn to head to your car, "I really appreciate your arranging for me to visit the sleep lab."

"Glad to do it," I respond, "and, oh by the way, ..."

"Yes?"

"Pleasant dreams!" 